\title{
Aplicação exógena de tiamina em arroz de terras altas submetido ao déficit hídrico
}

\author{
Exogenous application of thiamine on upland rice summited to water deficit
}

\section{Eduardo Pradi Vendruscolo ${ }^{1 *}$, Aliny Heloísa Alcântara Rodrigues ${ }^{2}$, Paulo Ricardo de Oliveira ${ }^{2}$, Rodrigo Andrade Leitão ${ }^{2}$, Luiz Fernandes Cardoso Campos $^{2}$, Alexsander Seleguini ${ }^{3}$, Sebastião Ferreira de Lima ${ }^{4}$}

\author{
1'Universidade Estadual de Mato Grosso do Sul, Cassilândia, MS, Brasil. *Autor para correspondência: agrovendruscolo@gmail.com. \\ ${ }^{2}$ Universidade Federal de Goiás, Goiânia, GO, Brasil. \\ ${ }^{3}$ Universidade Federal do Triângulo Mineiro, Iturama, MG, Brasil. \\ ${ }^{4}$ Universidade Federal de Mato Grosso do Sul, Chapadão do Sul, MS, Brasil.
}

Submissão: 19/02/2019 / Aceite: 10/12/2019

\begin{abstract}
RESUMO
A ocorrência de déficit hídrico durante o ciclo produtivo do arroz de terras altas, pode resultar em menor desenvolvimento vegetativo e produção. Neste sentido, verifica-se a possibilidade da utilização de produtos com efeito protetivo, tal como a vitamina B1. O objetivo deste trabalho foi avaliar os efeitos da aplicação exógena de tiamina, via foliar, durante e 30 dias após a emergência das plantas, sobre as características biométricas e produtivas de arroz de terras altas submetido a intervalo com déficit hídrico. O experimento foi delineado em blocos casualizados, com cinco tratamentos em cinco repetições, totalizando 25 parcelas experimentais. Os tratamentos foram assim definidos: $\mathrm{T} 1$ - controle sem aplicação da vitamina; T2 - aplicação de $50 \mathrm{mg} \mathrm{L}^{-1}$ de tiamina na emergência das plântulas; T3 - aplicação de 50 $\mathrm{mg} \mathrm{L}^{-1}$ de tiamina aos 30 dias após a emergência; $\mathrm{T} 4$ - aplicação de $100 \mathrm{mg} \mathrm{L}^{-1}$ de tiamina na emergência das plântulas; T5 - aplicação de $100 \mathrm{mg} \mathrm{L}^{-1}$ de tiamina aos 30 dias após a emergência. $O$ estresse hídrico foi aplicado quando as plantas estavam em estádio variando de V3 a V6. Foram avaliados os teores relativos de clorofilas "a", "b" e total, a altura de planta, o número de perfilhos, o comprimento e número de panículas por metro quadrado, a massa de 1000 grãos, a fertilidade de espiguetas e a produtividade. Destacou-se a aplicação da tiamina aos 30 dias após a emergência, elevando o comprimento de panícula, a massa de 1000 grãos e a fertilidade de espiguetas em $16,4 \%, 8,4 \%$ e $6,0 \%$, respectivamente. A aplicação da tiamina, como tratamento foliar, ameniza os efeitos da deficiência hídrica em sobre as características biométricas e produtivas de plantas de arroz de terras altas, principalmente quando aplicada 30 dias após a emergência das plantas e em concentração de $100 \mathrm{mg} \mathrm{L}^{-1}$.
\end{abstract}

PALAVRAS-CHAVE: Oriza sp., vitamina B1, estresse abiótico, proteção vegetal.

\section{ABSTRACT}

The occurrence of water deficit during the upland rice production cycle may result in lower vegetative development and yield. In this sense, it is possible to use products with a protective effect, such as vitamin B1. The objective of this work was to assess the effects of exogenous thiamine application, on leaves, during and 30 days after plant emergence, on the biometric and productive characteristics of upland rice submitted to an interval with water deficit. The experiment was designed in randomized blocks with five treatments. The treatments were defined as follows: T1 - control without vitamin application; T2 application of $50 \mathrm{mg} \mathrm{L}^{-1}$ thiamine in seedling emergence; T3 - application of $50 \mathrm{mg} \mathrm{L}^{-1}$ thiamine 30 days after emergence; T4 - application of $100 \mathrm{mg} \mathrm{L}^{-1}$ thiamine in seedling emergence; T5 - application of 100 $\mathrm{mg} \mathrm{L}^{-1}$ thiamine 30 days after emergence. Water stress was applied when the plants were at a stage ranging from V3 to V6. Relative levels of chlorophylls "a," "b," and total, plant height, number of tillers, length, and number of panicles per square meter, 1000 grains weight, spikelet fertility, and yield were assessed. Thiamine application was highlighted 30 days after emergence, increasing panicle length, 1000 grains weight, and spikelet fertility by $16.4 \%, 8.4 \%$, and $6.0 \%$, respectively. The application of thiamine as a foliar treatment mitigates the effects of water deficiency on the biometric and productive characteristics of upland rice plants, mainly when applied 30 days after plant emergence and at a concentration of $100 \mathrm{mg} \mathrm{L}^{-1}$.

KEYWORDS: Oriza sp., vitamin B1, abiotic stress, plant protection. 


\section{INTRODUÇÃO}

A ocorrência frequente de fenômenos climáticos anômalos tem causado preocupação quanto ao futuro da segurança alimentar em escala global (WHEELER \& VON BRAUM 2013). Para a agricultura, a ocorrência de secas prolongadas e o aumento da temperatura atmosférica são grandes barreiras à produtividade de diversas espécies de interesse econômico e alimentar, principalmente quando cultivadas em sistemas desprovidos de tecnologias de irrigação, como ocorre para o arroz de terras altas.

Apesar do arroz cultivado em sistemas não irrigados participar com apenas cerca de $10 \%$ do montante total da produção brasileira de arroz, este tem importância como cultura pioneira em áreas recémabertas ao cultivo e na rotação de culturas. No entanto, a baixa produtividade obtida nesse sistema (2.028 $\mathrm{kg} \mathrm{ha}^{-1}$ ), condicionada pelas condições ambientais, tem tornado esse tipo de cultivo pouco atrativo, ocasionando diminuição da área cultivada (OLIVEIRA NETO 2015). Em sistemas dependentes da disponibilidade de água pluviométrica, a ocorrência de secas prolongadas, principalmente durante a floração e o enchimento de grãos, pode vir a ocasionar elevadas perdas na produção de grãos em diversas regiões do país (OLIVEIRA NETO 2015).

O déficit hídrico pode levar ao comprometimento do funcionamento fisiológico das plantas de arroz, afetado seu desenvolvimento vegetativo e a reprodução (TERRA et al. 2015). Dentre as alterações morfofisiológicas, que ocorrem durante a exposição ao estresse, pode ser citada a diminuição dos teores relativos de água intracelular, o que culmina em menor capacidade fotossintética e de troca gasosa e consequentemente em um menor acúmulo de reservas energéticas utilizadas em diferentes estágios do desenvolvimento (AWASTHI et al. 2014, ZHOU et al. 2017).

O melhoramento genético consta como a principal ferramenta para a obtenção de materiais resistentes à diferentes estresses bióticos e abióticos. No entanto, a utilização de tecnologias complementares pode colaborar para a amenização das perdas a curto prazo. A inserção de elementos com ação bioestimulante e protetiva tem ganhado espaço nesse contexto. Além dos diversos compostos já estudados, entre os quais destacam-se aqueles de caráter hormonal, nutricional e biológico, observa-se a utilização potencial de outros elementos, tais como as vitaminas (HENDAWY \& EL-DIN 2010, BEDOUR \& RAWIA 2011, MAHGOUB et al. 2011, SOLTANI et al. 2014, VENDRUSCOLO et al. 2017).

A tiamina, ou vitamina B1, apresenta potencial para aplicação em sistemas de produção de espécies cultivadas, pois tem papel na proteção vegetal (GOYER 2010), atuando como promotor da produção de metabólitos secundários, que agem nos tecidos fotossintéticos a fim de evitar a oxidação de seus componentes (KAYA et al. 2015). Essa vitamina também atua como regulador do metabolismo de carbono, na síntese de proteínas (KAYA et al. 2015), induz o acúmulo de reservas nos tecidos vegetais (BARAKAT 2003) e de processos metabólicos celulares como coenzima (GOYER 2010), os quais condicionam o desenvolvimento dos vegetais (TAIZ et al. 2017).

Desta maneira, objetivou-se neste trabalho avaliar os efeitos da aplicação exógena de tiamina, via foliar, durante e 30 dias após a emergência das plantas, sobre as características biométricas e produtivas de plantas dede arroz de terras altas submetidas submetido a intervalo com estresse déficit hídrico.

\section{MATERIAL E MÉTODOS}

O estudo foi conduzido em ambiente protegido, estilo arco, coberto com lona de polietileno transparente, presente na área experimental pertencente à Escola de Agronomia da Universidade Federal de Goiás em Goiânia, Goiás, situada na região central do Brasil (16 40' S, 49 $15^{\prime}$ W e altitude de 750 m). Esta região possui clima Aw, segundo classificação de KÖPPEN-GEIGER (CARDOSO et al. 2014) caracterizado por clima tropical com estação chuvosa de outubro a abril e um período com precipitações inferiores a $100 \mathrm{~mm}$ mensais entre maio a setembro. As temperaturas médias mensais variam de 20,8 ${ }^{\circ} \mathrm{C}$, nos meses de junho e julho, a $25,3^{\circ} \mathrm{C}$ no mês de outubro (CARDOSO et al. 2014).

Em vasos com capacidade para $18 \mathrm{dm}^{3}$, foi realizada a semeadura de 10 grãos de arroz de terras altas (cv. Primavera) no dia 01 de dezembro de 2016. As sementes foram dispostas em uma linha na porção central do vaso, em profundidade de $3 \mathrm{~cm}$, sendo que apenas três plantas foram mantidas após o início do perfilhamento. A irrigação foi realizada diariamente por fitas gotejadoras instaladas sobre os vasos. Não houve ocorrência de doenças ou insetos-praga durante a condução das plantas. Também não foi realizada a correção do solo, tão pouco adubações com quaisquer nutrientes.

O solo utilizado foi classificação como Latossolo Vermelho (SANTOS et al. 2013) e apresenta a seguintes características químicas: $\mathrm{Ca}^{2+}: 3,2 \mathrm{cmol}_{\mathrm{C}} \mathrm{dm}^{-3}, \mathrm{Mg}^{2+}: 1,5 \mathrm{cmol}_{\mathrm{c}} \mathrm{dm}^{-3}, \mathrm{~K}^{+}: 52,0 \mathrm{mg} \mathrm{dm}^{-3}, \mathrm{P}($ Mehlich I): $28,0 \mathrm{mg} \mathrm{dm}^{-3}$, Matéria Orgânica: $1,6 \%, \mathrm{Al}^{3+}: 0,0 \mathrm{cmol}_{\mathrm{c}} \mathrm{dm}^{-3}, \mathrm{H}+\mathrm{Al}: 1,5 \mathrm{cmol}_{\mathrm{C}} \mathrm{dm}^{-3}$ e valores de $\mathrm{pH}\left(\mathrm{CaCl}_{2}\right)$ : 5,6, Capacidade de troca de cátions: $6,33 \mathrm{cmol}_{\mathrm{c}} \mathrm{dm}^{-3}$, Saturação por bases: $77,0 \%$, em análise realizada 
segundo a metodologia proposta por DONAGEMMA et al. (2011). A análise granulométrica do solo, segundo a metodologia desenvolvida por SILVA (2009), apresentou $270 \mathrm{~g} \mathrm{~kg}^{-1}$ de argila, $200 \mathrm{~g} \mathrm{~kg}^{-1}$ de silte e $530 \mathrm{~g} \mathrm{~kg}^{-1}$ de areia na camada $0-0,2 \mathrm{~m}$ do solo.

O experimento foi delineado em blocos casualizados, com cinco tratamentos em cinco repetições, totalizando 25 unidades experimentais. Os tratamentos foram assim definidos: T1 - controle sem aplicação da vitamina; T2 - aplicação de $50 \mathrm{mg} \mathrm{L}^{-1}$ de tiamina na emergência das plântulas; T3 - aplicação de $50 \mathrm{mg}$ $\mathrm{L}^{-1}$ de tiamina aos 30 dias após a emergência; T4 - aplicação de $100 \mathrm{mg} \mathrm{L}^{-1}$ de tiamina na emergência das plântulas; T5 - aplicação de $100 \mathrm{mg} \mathrm{L}^{-1}$ de tiamina aos 30 dias após a emergência. Para a aplicação via foliar utilizou-se um borrifador manual contendo as soluções de cada tratamento. As plantas foram borrifadas com as soluções, de forma que houve molhamento homogêneo das folhas.

A fim de estabelecer-se o estresse hídrico, a irrigação foi suspensa quando as plantas estavam em estádio variando de V3 a V6 até a ocorrência do enrolamento do limbo foliar (REGUERA et al. 2013), caracterizando o estresse, o que se deu no sexto dia de suspensão da irrigação. Após esse período a irrigação foi retomada normalmente.

Aos 90 dias após a semeadura foi realizada a quantificação dos teores relativos de clorofilas "a", "b" e total, utilizando-se clorofilômetro digital (Clorofilog; Falker $\left.{ }^{\circledR}\right)$. As demais avaliações foram realizadas aos 110 dias após a semeadura, quando se constatou o ponto de colheita dos grãos. Nesse momento foram tomadas as alturas das plantas, o número de perfilhos, o comprimento e calculado número de panículas por metro quadrado. Os grãos foram colhidos a fim de determinar-se a massa de 1000 grãos, a fertilidade das panículas e a produtividade por vaso.

Os dados coletados foram submetidos à análise de variância, comparando-se as médias obtidas em cada tratamento pelo teste de Tukey $(p<0,05)$.

\section{RESULTADOS E DISCUSSÃO}

Verificou-se que os diferentes tratamentos com tiamina não resultaram em diferenças significativas entre si ou em relação ao tratamento controle, com pulverização de água sobre as plantas (Tabela 1). Esses resultados podem estar relacionados à técnica de aplicação, pois a pulverização das soluções e da água foi realizada sem a adição de um adjuvante. Assim, no momento da aplicação foi observado o escorrimento das soluções, das folhas para o colmo e solo, podendo ser este o motivo da não efetividade das vitaminas diretamente sobre os teores de clorofila.

Tabela 1. Resumo da análise de variância para os teores de clorofila a (CLA), b (CLB) e total (CLT), altura de plantas (ALT), comprimento de panícula (CP), número de panículas $\mathrm{m}^{-2}(\mathrm{NP})$, massa de grãos por vaso (MG), massa de mil grãos (MMG), número de espiguetas por panícula (NPS) e fertilidade de espiguetas (FE) de arroz de terras altas pulverizadas com diferentes concentrações de tiamina durante e após 30 dias da emergência.

Table 1. Summary of the variance analysis for the levels of chlorophyll a (CLA), b (CLB), total (CLT), and plant height $(A L T)$, panicle length (CP), number of panicles $m^{-2}(N P)$, grain weight per pot (MG), 1000 grains weight (MMG), number of spikelets per panicle (NPS) and spikelet fertility (FE) of upland rice sprayed with different concentrations of thiamine during and after 30 days of emergence.

\begin{tabular}{|c|c|c|c|c|c|c|}
\hline & $\begin{array}{l}\mathrm{FV} \rightarrow \\
\mathrm{GL} \rightarrow\end{array}$ & $\begin{array}{c}\text { Bloco } \\
4\end{array}$ & $\begin{array}{c}\text { Tratamento } \\
4\end{array}$ & $\begin{array}{c}\text { Erro } \\
16\end{array}$ & CV (\%) & Média \\
\hline Váriavel & Unidade $\downarrow$ & \multicolumn{3}{|c|}{------quadrado médio-------- } & & \\
\hline CLA & (SPAD) & $17,778^{\text {ns }}$ & $17,228^{*}$ & 4,823 & 7,20 & 30,49 \\
\hline CLB & (SPAD) & $86,000^{\text {ns }}$ & $306,000^{\mathrm{ns}}$ & 119,750 & 10,50 & 104,20 \\
\hline CLT & (SPAD) & $7,102^{\text {ns }}$ & $21,611^{\mathrm{ns}}$ & 12,106 & 7,60 & 45,80 \\
\hline ALT & $(\mathrm{cm})$ & $0,598^{\mathrm{ns}}$ & $3,698^{* *}$ & 0,585 & 2,95 & 25,97 \\
\hline $\mathrm{CP}$ & $(\mathrm{cm})$ & $159,449^{\text {ns }}$ & $109,029^{\mathrm{ns}}$ & 145,965 & 7,15 & 169,00 \\
\hline NP & (panícula $\mathrm{m}^{-2}$ ) & $8,771^{\mathrm{ns}}$ & $33,790^{* *}$ & 4,755 & 2,31 & 94,50 \\
\hline$M G$ & $\left(\right.$ g vaso $\left.^{-1}\right)$ & $2,369^{\text {ns }}$ & $1,921^{\mathrm{ns}}$ & 3,875 & 5,51 & 35,75 \\
\hline MMG & (g) & $0,547^{\mathrm{ns}}$ & $1,265^{\text {ns }}$ & 1,660 & 12,30 & 10,48 \\
\hline NPS & $\left(n^{\circ}\right)$ & $3,007^{\text {ns }}$ & $6,224^{\mathrm{ns}}$ & 10,325 & 6,95 & 46,22 \\
\hline FE & $(\%)$ & $30,966^{\text {ns }}$ & $13,316^{\mathrm{ns}}$ & 13,914 & 4,10 & 90,88 \\
\hline
\end{tabular}


O escorrimento das soluções até o solo pode ter proporcionado a absorção deste elemento pelas raízes resultando em diferenças significativas para as características de comprimento de panícula, massa de mil grãos e fertilidade de espiguetas. No entanto, os tratamentos não afetaram o número de panículas por $\mathrm{m}^{2}$, a massa de grãos por $\mathrm{m}^{2}$ e o número de espiguetas por panícula (Tabela 1). VENDRUSCOLO et al. (2017), ao realizarem estudos acerca da aplicação de diferentes doses de tiamina em Brassica juncea L., demonstraram que a aplicação via solo é eficaz e propicia o desenvolvimento dos órgãos aéreos.

Verificou-se que o comprimento da panícula foi incrementado com a aplicação de $100 \mathrm{mg} \mathrm{L}^{-1}$ de tiamina aos 30 dias após a emergência das plântulas de arroz (Figura 1A). No entanto não houve diferença significativa para os demais tratamentos com aplicação da vitamina. Em relação ao tratamento controle, houve um incremento do comprimento da panícula de $4,6 \mathrm{~cm}$, equivalente a $16,4 \%$.
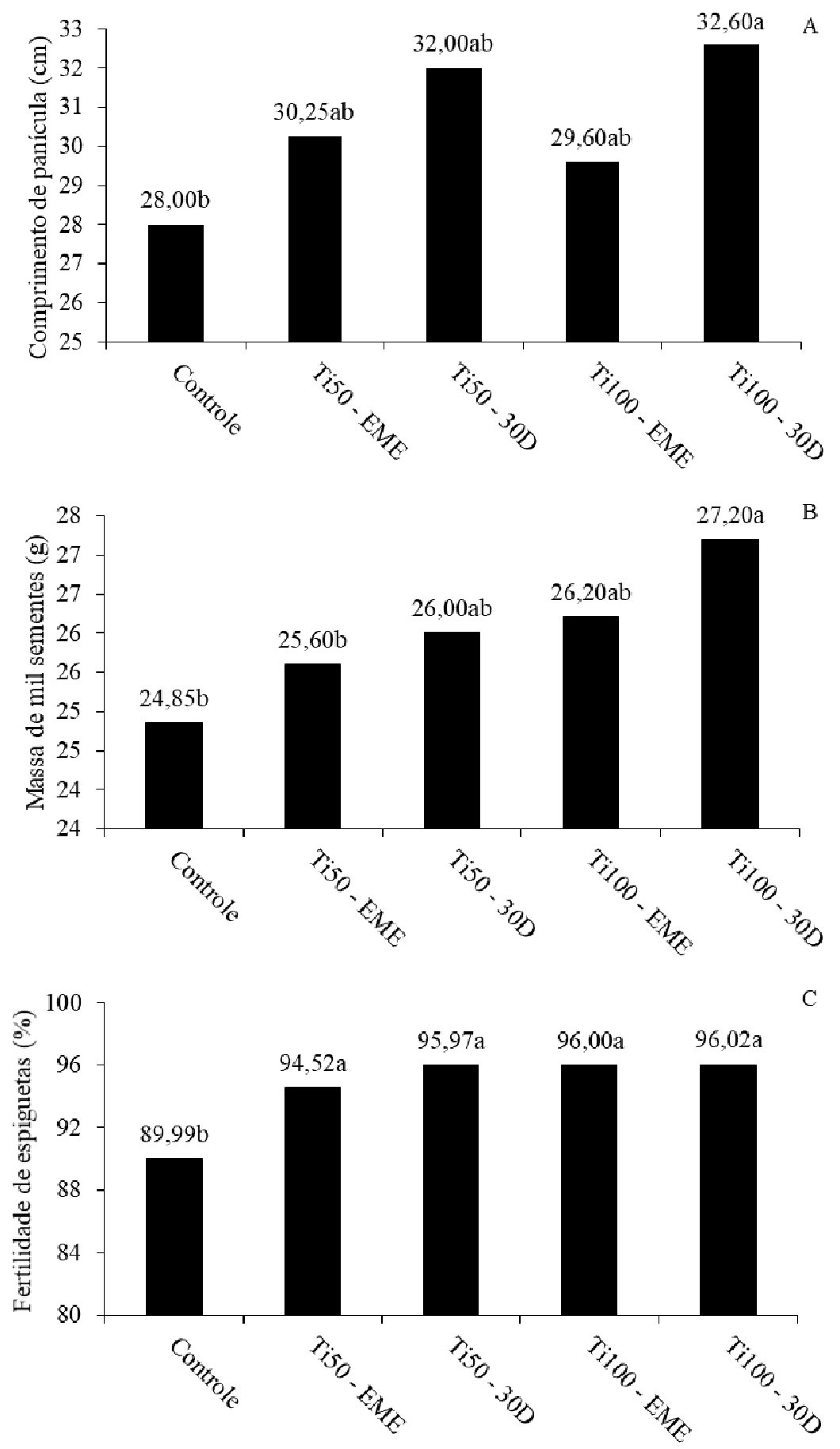

Figura 1. Comprimento de panícula, massa de mil grãos e fertilidade de espiguetas de plantas de arroz de terras altas pulverizadas com diferentes concentrações de tiamina durante e após 30 dias da emergência.

Figure 1. Panicle length, 1000 grains weight, and spikelets fertility of upland rice plants sprayed with different concentrations of thiamine during and after 30 days of emergence. 
Para a massa de mil grãos, observou-se resposta positiva e significativa com a aplicação de $100 \mathrm{mg}$ $\mathrm{L}^{-1}$ de tiamina aos 30 dias após a emergência das plântulas de arroz, apenas em relação ao tratamento controle e a aplicação de $50 \mathrm{mg} \mathrm{L}^{-1}$ de tiamina na emergência (Figura 1B). Comparativamente ao tratamento controle, o tratamento de maior eficácia culminou em elevação de $9,46 \%$ ou $2,35 \mathrm{~g}$ da massa de mil grãos.

A aplicação da tiamina foi efetiva para a obtenção de maior fertilidade das espiguetas, sendo que todos os tratamentos contendo a vitamina foram significativamente superiores ao tratamento controle (Figura 1C). Os ganhos em fertilidade chegaram a 4,5\%, 6,0\%, 6,0\% e 6,0\%, comparativamente aos tratamentos com aplicação em emergência e aos 30 dias de 50 e $100 \mathrm{mg} \mathrm{L}^{-1}$, respectivamente.

Os efeitos deletérios causados pelo déficit hídrico foram observados em experimento com diversas linhagens de arroz de terras altas, submetidas à $50 \%$ da lâmina ideal de irrigação após os 30 dias após a emergência das plantas. Nesse experimento NUNES et al. (2012) observaram que o estresse causou a elevação da quantidade de espiguetas inférteis e a diminuição da massa de 100 grãos em um número grande de linhagens. Essa queda da fertilidade e da massa dos grãos está relacionada ao comprometimento do sistema fisiológico da planta (TERRA et al. 2015). A diminuição da capacidade fotossintética e de troca gasosa, alavancadas pela diminuição dos teores relativos de água no interior das células, resulta em menor acúmulo das reservas energéticas, essenciais ao desenvolvimento das plantas (AWASTHI et al. 2014, ZHOU et al. 2017) e sua proteção frente a incidência de novos estresses (TAIZ et al. 2017).

Neste sentido, a aplicação da tiamina pode promover a amenização do estresse causado pela deficiência hídrica pela promoção da resistência. A aplicação exógena de tiamina incrementa a produção de metabólitos secundários responsáveis pela proteção dos tecidos vegetais através da ação antioxidante, protegendo e melhorando as condições do fotossistema (HASSANEIN et al. 2009, GOYER 2010, KAYA et al. 2015). Essa proteção resulta em um maior acúmulo de reservas energéticas e nutricionais (BARAKAT 2003), auxiliando na manutenção dos tecidos durante a ocorrência do estresse (TAIZ et al. 2017).

Os efeitos protetivos da aplicação exógena de tiamina também foram observados para a cultura do milho, quando diferentes materiais genéticos, expostos ao estresse salino, foram tratados com tiamina via foliar e via grãos. Esses materiais apresentaram maior capacidade de desenvolvimento e funcionamento do sistema fotossintético (KAYA et al. 2015). Em videira a aplicação de tiamina diminuiu a severidade da infecção por míldio, suprimindo a capacidade de esporulação do patógeno e retardando a morte das células vegetais (BOUBAKRI et al. 2012). Para plantas de arroz, foi constatado que a aplicação exógena de tiamina atua no aumento da resistência a nematoides (HUANG et al. 2016), fungos e bactérias de importância econômica (AHN et al. 2005).

A tiamina proporciona ainda, em algumas espécies, efeito bioestimulante incrementando características biométricas e reprodutivas. Para espécies como calêndula, dália, gladíolo, funcho e mostarda a aplicação exógena de tiamina eleva os teores de clorofilas nos tecidos foliares, incrementa a altura e o acúmulo de massa seca nos tecidos, além de promover o desenvolvimento de ramos, flores e grãos (HENDAWY \& EL-DIN 2010, BEDOUR \& RAWIA 2011, MAHGOUB et al. 2011, SOLTANI et al. 2014, VENDRUSCOLO et al. 2017).

Para culturas de interesse agronômico, a aplicação exógena pode constar como uma técnica, tanto visando o melhor desenvolvimento dos vegetais, quanto para a amenização dos efeitos provenientes dos estresses ambientais. Apesar de haverem estudos demonstrando a viabilidade da aplicação desse elemento (VENDRUSCOLO et al. 2018), a continuidade das pesquisas, em diferentes condições experimentais, é essencial à implementação das vitaminas na produção vegetal.

\section{CONCLUSÃO}

A aplicação da tiamina, como tratamento foliar, ameniza os efeitos da deficiência hídrica em sobre as características biométricas e produtivas de plantas de arroz de terras altas, principalmente quando aplicada 30 dias após a emergência das plantas e em concentração de $100 \mathrm{mg} \mathrm{L}^{-1}$.

\section{REFERÊNCIAS}

AHN IP et al. 2005. Vitamin B1 functions as an activator of plant disease resistance. Plant Physiology 138: 1505-1515. AWASTHI RP et al. 2014. Individual and combined effects of transient drought and heat stress on carbon assimilation and seed filling in chickpea. Functional Plant Biology 41: 1148-1167.

BARAKAT H. 2003. Interactive effects of salinity and certain vitamins on gene expression and cell division. International Journal of Agriculture and Biology 5: 219-225.

BEDOUR AAL \& RAWIA AE. 2011. Improving gladiolus growth, flower keeping quality by using some vitamin application. Journal of American Science 7: 169-174. 
BOUBAKRI H et al. 2012. Thiamine induced resistance to Plasmopara viticola in grapevine and elicited host-defense responses, including HR like-cell death. Plant Physiology and Biochemistry 57: 120-133.

CARDOSO MRD et al. 2014. Classificação climática de KÖPPEN-GEIGER para o estado de Goiás e o Distrito Federal. Acta Geográfica 8: 40-55.

DONAGEMMA GK et al. 2011. Manual de métodos de análise de solo. 2.ed. Rio de Janeiro: EMBRAPA. 212p.

GOYER A. 2010. Thiamine in plants: aspects of its metabolism and functions. Phytochemistry 71: 1615-1624.

HASSANEIN RA et al. 2009. Physiological effects of nicotinamide and ascorbic acid on Zea mays plant grown under salinity stress. Changes in growth, some relevant metabolic activities and oxidative defense systems. Research Journal of Agriculture and Biological Sciences 5: 72-81.

HENDAWY SF \& EZZ EL-DIN AA. 2010. Growth and yield of Foeniculum vulgar var. Azoricum as influensed by some vitamins and amino acids. Ozean Journal Applied Science 3: 113-123.

HUANG WK et al. 2016. Thiamine-induced priming against root-knot nematode infection in rice involves lignification and hydrogen peroxide generation. Molecular Plant Pathology 17: 614-624.

KAYA C et al. 2015. Exogenous application of thiamin promotes growth and antioxidative defense system at initial phases of development in salt-stressed plants of two maize cultivars differing in salinity tolerance. Acta Physiologiae Plantarum 37: 1741.

MAHGOUB HM et al. 2011. Response of Dahlia pinnata L. plant to foliar spray with Putrescine and Thiamine on growth, flowering and photosynthetic pigments. American-Eurasian Journal of Agricultural \& Environmental Sciences 10: 769775.

OLIVEIRA NETO AA. 2015. A cultura do arroz. Brasília: Conab. 179p.

REGUERA $M$ et al. 2013. Stress-induced cytokinin synthesis increases drought tolerance through the coordinated regulation of carbon and nitrogen assimilation in rice. Plant Physiology 163: 1609-1622.

SANTOS HG et al. 2013. Sistema Brasileiro de Classificação de Solos. 3.ed. Brasília: Embrapa. 342p.

SOLTANI Y et al. 2014. Response of growth, flowering and some biochemical constituents of Calendula officinalis L. to foliar application of salicylic acid, ascorbic acid and thiamine. Ethno-Pharmaceutical Products 1: 37-44.

SILVA FC. 2009. Manual de análises químicas de solos, plantas e fertilizantes. Rio de Janeiro: Embrapa. 623p.

TAIZ L et al. 2017. Fisiologia e desenvolvimento vegetal. 6.ed. Porto Alegre: Artmed. 888p.

NUNES TV et al. 2012. Aspectos produtivos de linhagens de arroz de terras altas sob déficit hídrico. Revista Brasileira de Ciências Agrárias 7: 52-57.

TERRA TGR et al. 2015. Características de tolerância à seca em genótipos de uma coleção nuclear de arroz de terras altas. Pesquisa Agropecuária Brasileira 50: 788-796.

VENDRUSCOLO EP et al. 2017. Aplicação de niacina ou tiamina promove incremento no desenvolvimento de mostarda. Cultura Agronômica 26: 433-442.

VENDRUSCOLO EP et al. 2018. Viabilidade econômica do cultivo de milho doce submetido à inoculação com Azospirillum brasilense e soluções de tiamina. Amazonian Journal of Agricultural and Environmental Sciences 61: 1-7.

WHEELER T \& VON BRAUN J. 2013. Climate change impacts on global food security. Science 341: 508-513.

ZHOU R et al. 2017. Drought stress had a predominant effect over heat stress on three tomato cultivars subjected to combined stress. BMC Plant Biology 17: 1-13. 